\title{
Effect of bromocriptine on maturity onset diabetes
}

\author{
*A. H. BARNeTt \\ B.Sc., M.R.C.P. \\ K. GAILER \\ B.Sc.
}

\author{
C. Chapman \\ B.Sc., Ph.D.
}

C. J. HAYTER

B.Sc., F.R.C.P.

Department of Nuclear Medicine, Leeds General Infirmary, Leeds

\begin{abstract}
Summary
The effect of the dopamine agonist, bromocriptine, and the dopamine antagonist, metoclopramide, on glucose tolerance was examined in maturity onset diabetics and normal subjects. After bromocriptine there was a lowered fasting blood glucose and improved glucose tolerance in the diabetics. The controls showed an initial improvement in glucose tolerance. A reduction in insulin levels and a marked fall in plasma prolactin was observed in all subjects. Growth hormone concentrations were low and unaffected in the diabetics, and there was an inconsistent rise in the normals. After metoclopramide there was some impairment in glucose tolerance in the normal subjects, but this was not significant in the diabetics. There was also a marked prolactin release in all subjects, but no significant effect on insulin or growth hormone. It is concluded that bromocriptine lowers the blood glucose and improves glucose tolerance in maturity onset diabetics. This action may be the result of the lowered prolactin which occurred without a concomitant rise in growth hormone.
\end{abstract}

\section{Introduction}

Growth hormone is a diabetogenic hormone and there is now evidence that prolactin has similar diabetogenic properties (Landgraf et al., 1975, 1977; Woolf et al., 1977). The ergot alkaloid, bromocriptine has been shown to improve glucose tolerance in patients with acromegaly and diabetes, and in some cases this improvement has occurred without changes in growth hormone levels. Various explanations have been offered for this phenomenon (Thorner et al., 1975; Besser et al., 1976; Camanni et al., 1975).

The authors studied the effects of bromocriptine on glucose tolerance in patients with maturity onset diabetes and in normal subjects. As bromocriptine

\footnotetext{
* Present address: Diabetic Unit, King's College Hospital, Denmark Hill, London SE5 9RS
}

is a dopamine agonist, they also examined the effects on glucose tolerance of a dopamine antagonist, metoclopramide.

\section{Patients and methods}

Eight patients with maturity onset diabetes (5 female), and 6 normal subjects (5 male), were studied. The diabetics were all controlled on diet with or without oral hypoglycaemic therapy, and the normal subjects had normal glucose tolerance. The age range of the diabetics was 40-72 years and that of the controls was 22-34 years. They were not age-matched but each patient acted as his own control.

Plasma glucose and growth hormone, prolactin and insulin concentrations were assayed before, and $15,30,60,90,120,150$ and $180 \mathrm{~min}$ after ingestion of glucose $(50 \mathrm{~g})$ in fasting subjects under the following conditions: (a) Oral glucose only (control); (b) bromocriptine, $2.5 \mathrm{mg}$ orally, administered with a glass of water $2 \mathrm{hr}$ before the glucose. A fasting blood sample was also taken just before the bromocriptine was given; (c) metoclopramide, $10 \mathrm{mg}$ i.v. administered as a bolus just before the glucose, but after the fasting sample was obtained.

The order of tests was randomized, with 7 days between tests in each patient. All blood samples were drawn from a peripheral arm vein through a butterfly cannula kept patent with heparin-saline.

Before the administration of each glucose load, oral hypoglycaemic therapy was discontinued for $48 \mathrm{hr}$, and each person was fasted overnight.

For prolactin and growth hormone determinations a post-precipitation double antibody radioimmunoassay technique was used. For prolactin, the MRC research standard A71/222 and for growth hormone the first IRP standards were used. For insulin, a preprecipitation double antibody radioimmunoassay was used with Wellcome Reagent-Human Insulin Standard Plasma glucose was determined enzymatically. 
Intravenous glucose tolerance tests were later performed on 7 different patients with maturity onset diabetes, before and after bromocriptine, with a period of one week between tests. The order of the tests was randomized and each subject was fasted overnight. Only 2 patients were on hypoglycaemic therapy and this was temporarily discontinued 48 $\mathrm{hr}$ before the test. A fasting blood sample for glucose determination was taken just before the injection of $25 \mathrm{~g}$ glucose (as $50 \%$ solution) into a cannulated antecubital vein over a period of $4 \mathrm{~min}$. Blood samples for glucose determinations were then taken at exactly $10-\mathrm{min}$ intervals for one hour. The rate of fall of plasma glucose concentrations was expressed as a $\mathrm{K}$ value, derived from the formula

$$
\mathrm{K}=\frac{\log \mathrm{e}^{2}}{t}
$$

where $t$ is the time in minutes for the excess blood glucose to be halved; $t$ was calculated by plotting on semi-logarithmic paper time (min) $v$. blood glucose concentration.

The results were analysed by Wilcoxon's matched pairs signed rank test for non-parametric data.

\section{Results}

Glucose

The normal subjects all had normal glucose tolerance. After bromocriptine the plasma glucose curve was flattened with a significant reduction at $15 \mathrm{~min}$, and a significant increase at $120 \mathrm{~min}$ when compared with the controls (Fig. 1a).

Seven of the 8 diabetics, all of whom had impaired control curves, showed a marked improvement in glucose tolerance after bromocriptine. This improvement was maintained throughout the time of testing although it was not significant at 150 and $180 \mathrm{~min}$. There was also a significant reduction of fasting blood glucose (Fig. 1a).

After metoclopramide there was a significant impairment of glucose tolerance in the control subjects at 15 and $60 \mathrm{~min}(P<0.01)$, but no significant difference after this time. There was no significant effect in the diabetics (Fig. 1b).

\section{Insulin}

Plasma insulin was initially reduced in the diabetics after bromocriptine, although not significantly, at 120, 150 and $180 \mathrm{~min}$ (Fig. 2). There was an initial lowering also in the normal subjects $(P<0.05)$ but later the values were comparable to those obtained without bromocriptine. Metoclopramide had no significant effect on plasma insulin.

\section{Prolactin}

There was a marked fall in plasma prolactin after bromocriptine administration in both diabetic and normal subjects and this persisted throughout the time of the test (Fig. 3).

Prolactin showed a significant rise after metoclopramide in both diabetic and normal subjects
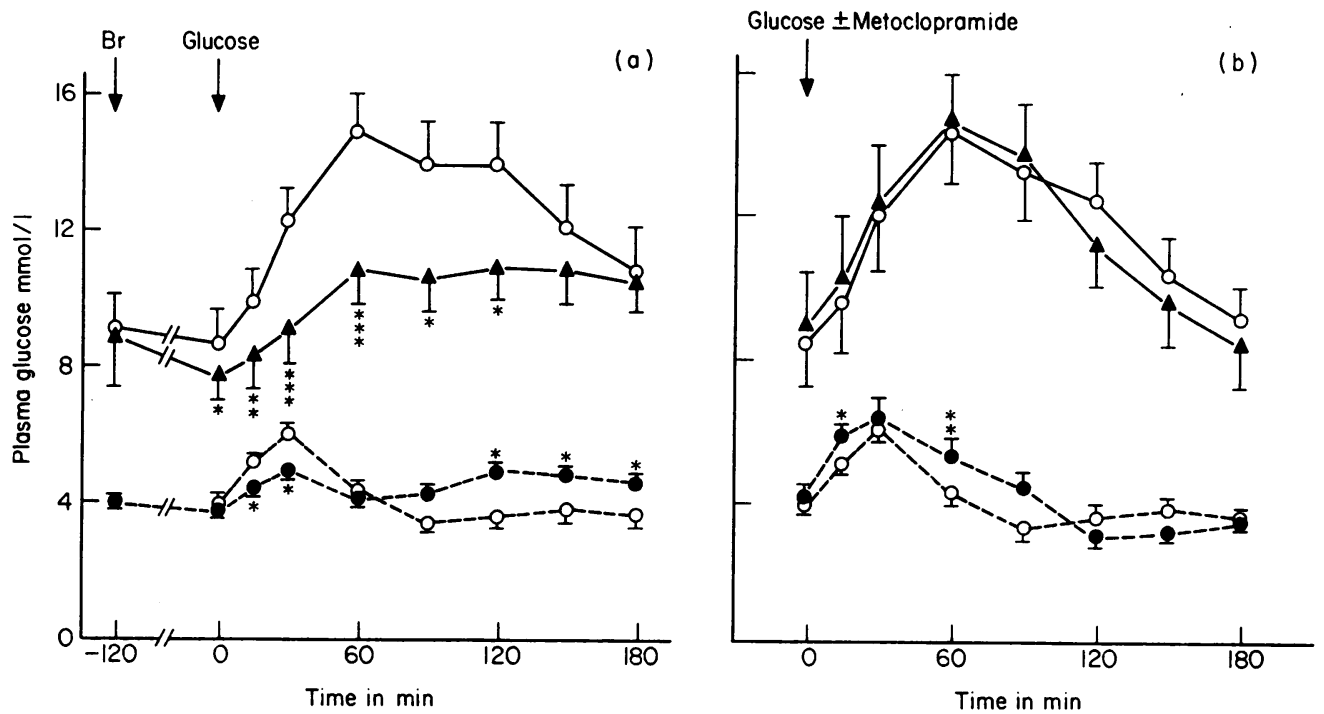

Fig. 1. Blood glucose ( \pm s.e. mean) after $50 \mathrm{~g}$ oral glucose load in 6 normal subjects and 8 with maturity onset diabetes, (a) with and without pre-treatment with bromocriptine (Br) $2.5 \mathrm{mg}$ orally. Asterisks indicate significant difference $\left(* P<0.05,{ }^{* *} P<0.02,{ }^{* * *} P<0.01\right)$. (b) with and without pre-treatment with metoclopramide $10 \mathrm{mg}$ i.v. Asterisks indicate significant difference $(* P<0.05 ; * * P<0.01)$. 
$(P<0.001)$ and this was maintained throughout the test, although the greatest rise was in the hour after metoclopramide administration.

\section{Growth hormone}

There was an inconsistent growth hormone increase in the normal subjects $2 \mathrm{hr}$ after bromocriptine administration and there was subsequent hormone reduction after the glucose load. Four of the 6 subjects had a marked response to bromocriptine and 2 failed to respond at all. In the diabetics, however, basal levels were low, but within the normal range, and were unaltered by glucose loading, bromocriptine or by metoclopramide.

\section{Intravenous glucose tolerance}

All the diabetics showed improvement in glucose tolerance after bromocriptine $(P<0.01)$, markedly so in 4 cases (Table 1).

\section{Discussion}

There was a marked improvement in both fasting plasma glucose concentration and in glucose tolerance, after bromocriptine in the maturity onset diabetics. Seven of the 8 patients tested showed this improvement, although the eighth patient showed very little response and little change in

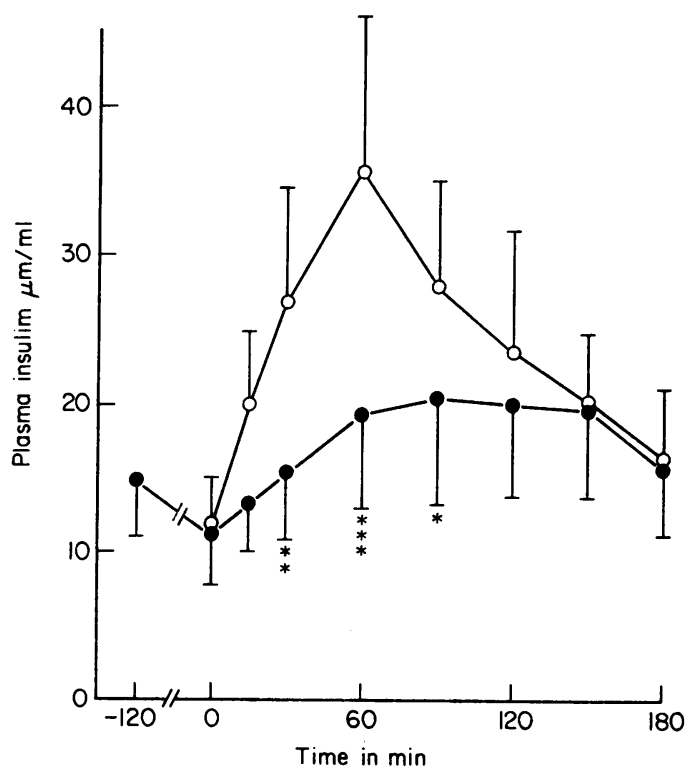

FIG. 2. Plasma insulin ( \pm s.e.mean) after $50 \mathrm{~g}$ oral glucose load in 8 patients with maturity onset diabetes with and without pretreatment with bromocriptine $2.5 \mathrm{mg}$ orally. Asterisks indicate significant difference (* $\left.P<0.05 ;{ }^{* *} P<0.02 ;{ }^{* * *} P<0.01\right)$. $\bigcirc$ Glucose, $\mathrm{Br}+$ glucose. hormonal pattern. The dose of bromocriptine used throughout was a small one; it is possible that he would have responded to a higher dose.

Plasma insulin was lowered after bromocriptine and so changes in insulin secretion would not account for the improvement in glucose tolerance. This occurrence was presumably secondary to lowering of blood glucose. The improvement may be attributable to the decrease in plasma prolactin, a hormone which slows down glucose utilization. There was a substantial reduction in prolactin after bromocriptine in all subjects, which is a well known observation (Rozencweig et al., 1973; Del Pozo

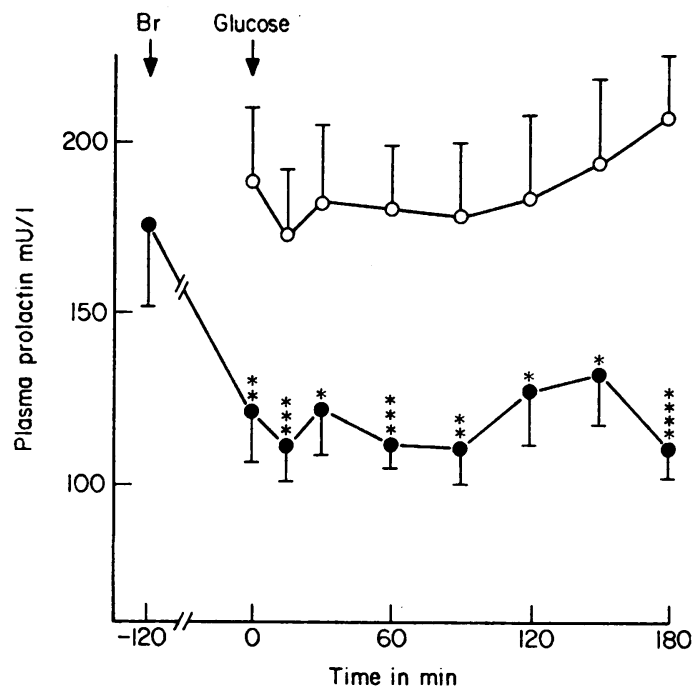

Fig. 3. Plasma prolactin ( \pm s.e.mean) after $50 \mathrm{~g}$ oral glucose load in 8 maturity onset diabetics, with and without pretreatment with bromocriptine $2.5 \mathrm{mg}$ orally. Asterisks indicate significant difference $(* P<0.05$; ** $P<0.02$; *** $P<0.01$; *** $P<0.001)$. O Glucose, $\mathrm{Br}+$ glucose.

TABLE 1. $\mathrm{K}$ values (rate of glucose disappearance from plasma) for 7 patients with maturity onset diabetes after intravenous glucose tolerance tests, with and without pre-treatment with bromocriptine $(\mathrm{Br}) 2.5 \mathrm{mg}$ orally

\begin{tabular}{ccc}
\hline Patient & $\begin{array}{c}\text { K value } \\
\text { (no Br) }\end{array}$ & $\begin{array}{c}\text { K value } \\
\text { (plus Br) }\end{array}$ \\
\hline 1 & 1.33 & 2.48 \\
2 & 0.94 & 1.16 \\
3 & 1.65 & 3.47 \\
4 & 1.10 & 1.29 \\
5 & 0.86 & 1.48 \\
6 & 0.96 & 1.00 \\
7 & 0.93 & 2.63 \\
\hline
\end{tabular}

$P<0.01$.

Normal range for $\mathrm{K}$ values in non-diabetics $=3.0$ to 4.9 . 
et al., 1972; Tolis, Pinter and Friesen, 1975; Gnudi, Lugori and Cavazzini, 1977). Hyperprolactinaemia from any cause has been shown to decrease glucose tolerance and increase insulin response (Landgraf et al., 1977). Suppression of basal prolactin concentration by bromocriptine may improve glucose tolerance and normalize glucose induced insulin release (Landgraf et al., 1977; Gnudi et al., 1977). These findings are similar to the observations of the present authors-bromocriptine, a dopamine agonist, improves glucose tolerance and lowers prolactin, whereas metaclopramide, a dopamine antagonist, tends to impair the glucose profile (significantly in the normal subjects) and raises prolactin levels. Prolactin may play an important role in the glucose homoeostasis of the body, and indeed it is known to increase during hypoglycaemia. The present findings would support the hypothesis (Landgraf et al., 1975, 1977; Woolf et al., 1977) that prolactin is a diabetogenic hormone.

The effect of bromocriptine on growth hormone was inconsistent, 4 out of 6 normal subjects responded markedly to bromocriptine with growth hormone release, but 2 failed to respond at all. The growth hormone response to bromocriptine may be the result of dopamine-like activity at the hypothalamic level. In the maturity onset diabetics, there was no effect on growth hormone after glucose, with or without bromocriptine or metoclopramide. These remained within the accepted basal range. In contrast, in studies carried out on insulin-dependent diabetics (Gnudi et al., 1977) basal growth hormone concentration was high and there was only partial suppression after oral glucose. Bromocriptine failed to suppress and, in fact, increased the growth hormone concentration.

A significant lowering of plasma prolactin, after bromocriptine, has been demonstrated in insulindependent diabetics (Gnudi et al., 1977). This was accompanied by an apparent improvement in glucose tolerance, although this was not statistically significant. In the insulin-dependent diabetics studied, however, there was a rise in the already high serum growth hormone. This difference may explain why the improvement in glucose tolerance in maturity onset diabetics is much more marked than in the insulin-dependent diabetics.

To counter a possible criticism that the hypoglycaemic properties of bromocriptine demonstrated may be due to slowed stomach emptying, rather than changes in hormone profile, the authors also measured the effect of bromocriptine on intravenous glucose tolerance tests in different maturity onset diabetics. The 7 subjects showed an improvement in glucose tolerance, markedly so in 4 cases. If bromocriptine has any effect on glucose tolerance by reducing stomach emptying, this effect is not marked.

It is concluded that bromocriptine has a hypoglycaemic action in maturity onset diabetics, and this may be due to a lowering of prolactin concentration which occurs without a concomitant increase in growth hormone concentration. The concept of prolactin being a diabetogenic hormone is supported.

\section{Acknowledgments}

The authors would like to thank $\mathrm{Dr}$ Wales and $\mathrm{Mr}$ Stickland, Department of Medicine, Leeds General Infirmary, for their help with the insulin assays. They would also like to thank Mrs A. Spink, Diabetic Dept, King's College Hospital, for typing the manuscript.

\section{References}

Besser, G.M., Thorner, M.O., Wass, J.A.H., Jones, A.E., Lowry, P.J., ReEs, L.H. \& Jones, A. (1976) Bromocriptine treatment of acromegaly. Quarterly Journal of Medicine, 45 (Abstract 180), 695.

Camanni, F., Massara, F., Belforte, L. \& Molinatti, G.M. (1975) Changes in plasma growth hormone levels in normal and acromegalic subjects following administration of 2-bromo-ergocryptine. Journal of Clinical Endocrinology and Metabolism, 40, 363.

Del Pozo, E., Brun del Re., R., Varga, L. \& Friesen, H. (1972) The inhibition of prolactin secretion in man by CB-154 (2-br- $\alpha$-ergocryptine). Journal of Clinical Endo-? crinology and Metabolism, 35, 768.

Gnudi, A., Lugari, R. \& Cavazzini, M.G. (1977) Variation of blood glucose and serum growth hormone, prolactin and insulin in subjects with insulin-dependent diabetes. Acta diabetologica latina, 14, 119.

Landgraf, R., Landgraf-Leurs, M.M., Weissmann, A., HÖRL, R., von Werder, K. \& SCRIBe, P.C. (1977) Prolactin: a diabetogenic hormone. Diabetologia, 13 (2), 99.

Landgraf, R., Weissmann, A., Landgraf-Leurs, M.M. \& v. WeRDER, K. (1975) Glucose tolerance and glucoseinduced insulin release in patients with hyperprolactinaemia. Acta endocrinologica. 78 (Suppl. 193), 65.

Rozencweig, M., Heuson, J.C., Bila, S., L'Hermite, M. \& ROBYN, C. (1973) Effects of 2-br- $\alpha$-ergocryptine, L-dopa and cyclic imides on serum prolactin in postmenopausal women. European Journal of Cancer, 9, 657.

Thorner, M.O., Chait, A., Aitken, M., Benker, G., Bloom, S.R., Mortimer, C.H., Sanders, P., Stuart MAson, A. \& Besser, G.M. (1975) Bromocriptine treatment of acromegaly. British Medical Journal, 1, 299.

Tolis, G., Pinter, E.J. \& Friesen, H.G. (1975) The acute effect of 2-bromo- $\alpha$-ergocryptine (CB 154 on anterior pituitary hormones and free fatty acids in man. International Journal of Clinical Pharmacology, 12, 281.

Woolf, P.D., LeE, L.A., LeEBaw, W., Thompson, D., Lilavivathana, U., Brodows, R. \& Campbell, R. (1977) Intracellular glucopenia causes prolactin release in man. Journal of Clinical Endocrinology and Metabolism, 45, 377. 